SCIENTIFIC LETTER

\title{
Short term prognosis of patients with acute coronary syndromes: the level of cardiac troponin T elevation corresponding to the "old" WHO definition of myocardial infarction
}

\author{
C J Knight, T R Keeble, S Wilson, J Cooper, A Deaner, K Ranjadayalan, A D Timmis
}

Heart 2005;91:373-374. doi: 10.1136/hrt.2003.031351

$\mathrm{T}$ raditionally, myocardial infarction (MI) has been diagnosed according to the World Health Organization criteria, which emphasises the importance of the clinical syndrome, electrocardiographic changes, and elevation of long standing but relatively non-specific markers of myocardial damage such as creatine kinase (CK). ${ }^{1}$

In 2000, a Joint European Society of Cardiology (ESC)/ American College of Cardiology (ACC) committee published a redefinition of MI, based upon raised serum concentrations of cardiac troponins. ${ }^{2}$ This has led to the inclusion of patients with lower levels of myocardial damage than was previously detectable. As a result future epidemiological studies will inevitably be skewed by the "new" definition with an increase in the numbers of patients diagnosed with MI, and an apparent improvement in overall prognosis likely to be related to a smaller proportion of patients with large transmural infarctions being exposed to the hazards of ventricular remodelling and heart failure. This has important implications for patients who may be unjustifiably concerned by information concerning their prognosis obtained from historical studies and unjustifiably penalised by financial institutions. For these reasons it is important to try and establish the level of troponin elevation that corresponds in terms of prognosis to the "old" WHO definition of MI so that patients and physicians can compare old and new data from registries and clinical trials.

\section{PATIENTS AND METHODS}

Of 1781 patients with acute coronary syndromes admitted to two East London hospitals during a two year period from January 2000, 804 with both cardiac troponin T (cTnT) and CK measurements constituted the study group. Patients with a first admission during that period were included if they fulfilled WHO criteria for acute MI or Braunwald criteria for class 3B unstable angina. The patients had a mean (SD) age of 64 (13) years, and $542(67 \%)$ were male.

Criteria for MI were any two of the following: cardiac chest pain lasting at least 30 minutes; $\geqslant 0.1 \mathrm{mV}$ ST elevation in at least one standard lead or $\geqslant 0.2 \mathrm{mV}$ ST elevation in two or more contiguous chest leads; $\mathrm{CK} \geqslant 400 \mathrm{IU} / \mathrm{l}$ (upper limit of reference range: $200 \mathrm{IU} / \mathrm{l}$ ). Criteria for Braunwald class 3B unstable angina were cardiac chest pain at rest within the preceding 48 hours not attributable to MI or to non-cardiac causes.

Baseline clinical characteristics including demographic, clinical, and biochemical data were collected prospectively by a dedicated cardiologist or research nurse and stored on a purpose built electronic database. The protocol for serum CK sampling included one sample being taken in the emergency department followed by samples being taken two consecutive mornings after admission. Serum CTnT samples were obtained approximately 12 hours after the onset of chest pain and analysed by quantitative immunoassay; concentrations $\geqslant 0.1 \mu \mathrm{g} / \mathrm{l}$ were defined a positive result. The coefficient of variation was less than $10 \%$ in both centres.

ECGs were categorised as showing new ST elevation, or new Q waves. Documented complications included cardiac death, and left ventricular failure (LVF). The diagnosis of LVF required there to be treatment with diuretics based on symptoms of breathlessness accompanied by physical findings of basal crepitations and/or a third heart sound.

Differences in categorical variables between the cardiac troponin tertiles were tested by the $\chi^{2}$ method.

\section{RESULTS}

Of the 804 patients, 26 patients (3.2\%) died in hospital (there were no non-cardiac deaths) and 122 patients (15.2\%) developed LVF. Analysis of the ECGs revealed that 203/804 $(25.2 \%)$ had new ST elevation, and 151/804 (18.8\%) developed new Q waves.

Two hundred and fifty patients had CK $\geqslant 400 \mathrm{IU} / \mathrm{l}$ and were classified as acute MI, representing $31.1 \%$ of the study group. Of these patients, $8.4 \%(21 / 250)$ died as a result of cardiac disease, and $24.5 \%$ (61/250) developed LVF. Of the patients studied, 51.4\% (126/250) had documented new ST elevation, and 47\% (117/250) developed new Q waves.

Analysis of complication rates by cTnT tertiles (table 1) shows a gradient of risk for combined death and LVF ranging from $10.7 \%(36 / 338)$ in the normal cTnT group, up to $27.2 \%$ $(41 / 151)$ in those with a cTnT $>1.1 \mu \mathrm{g} / \mathrm{l}$. It was only in the upper tertile of $\mathrm{cTnT}(>1.1 \mu \mathrm{g} / \mathrm{l})$ that Q wave development, LVF, and cardiac death become comparable to that seen in patients with acute MI diagnosed by "old" enzymatic criteria $(\mathrm{CK} \geqslant 400 \mathrm{IU} / \mathrm{l})$.

\section{DISCUSSION}

Cardiac troponins are widely used for risk stratification in the setting of both ST and non-ST elevation acute coronary syndromes. In non-ST elevation acute coronary syndromes, it has been shown that increasing concentrations of CTnT predict event rate at five months. Furthermore additional prognostic information can be gained when the cTnT concentration is combined with ST segment and $\mathrm{T}$ wave changes on the ECG. ${ }^{3}$

Following ST segment elevation MI, left ventricular function is the best individual predictor of mortality. ${ }^{4}$ Cardiac troponin concentration has already been shown to be able to predict patients with low ejection fraction. ${ }^{5}$ Rao

Abbreviations: $\mathrm{cTnT}$, cardiac troponin $\mathrm{T}$; CK, creatine kinase; LVF, left ventricular failure; MI, myocardial infarction; WHO, World Health Organization 
Table 1 Complication rates compared to cTnT and CK concentrations

\begin{tabular}{|c|c|c|c|c|c|}
\hline \multirow[b]{2}{*}{ End point } & \multirow{2}{*}{$\begin{array}{l}\text { Normal cTnT } \\
\begin{array}{l}\leqslant 0.01 \mu \mathrm{g} / \mathrm{l} \\
(\mathrm{n}=338)\end{array}\end{array}$} & \multicolumn{3}{|l|}{ cTnT positive } & \multirow{2}{*}{$\begin{array}{l}\text { CK } \\
\geqslant 400 \mathrm{IU} / \mathrm{I} \\
(\mathrm{n}=250)\end{array}$} \\
\hline & & $\begin{array}{l}\text { Tertile 1 } \\
\leqslant 0.26 \mu \mathrm{g} / \mathrm{l} \\
(\mathrm{n}=159)\end{array}$ & $\begin{array}{l}\text { Tertile } 2 \\
\leqslant 1.1 \mu g / / \\
(n=156)\end{array}$ & $\begin{array}{l}\text { Tertile } 3 \\
>1.1 \mu \mathrm{g} / \mathrm{l} \\
(\mathrm{n}=151)\end{array}$ & \\
\hline $\begin{array}{l}\text { LVF } \\
\text { Death } \\
\text { Death/LVF }\end{array}$ & $\begin{array}{l}33(9.9) \\
6(1.8) \\
36(10.7)\end{array}$ & $\begin{array}{l}24(15.1) \\
2(1.3) \\
24(15.1)\end{array}$ & $\begin{array}{l}29(18.6) \\
6(3.9) \\
30(19.2)\end{array}$ & $\begin{array}{l}36(23.8) \\
12(8) \\
41(27.2)\end{array}$ & $\begin{array}{l}61(24.5) \\
21(8.4) \\
68(27.2)\end{array}$ \\
\hline
\end{tabular}

For the upper tertile of cTnT ( $>1.1 \mu \mathrm{g} / \mathrm{l})$, the risk of LVF, death, and combined death/LVF was significantly greater than that of all the other troponin groups $(p<0.003)$.

Percentage figures of each group are shown in brackets.

CK, creatine kinase, cTnT, cardiac troponin T; LVF, left ventricular failure.

and colleagues ${ }^{5}$ found that patients admitted after first acute MI defined by the traditional WHO criteria, with a cTnT $\geqslant 2.8 \mu \mathrm{g} / \mathrm{l}(12-24$ hours after admission), identified patients with an ejection fraction $<40 \%$ with a sensitivity of $95.5 \%$ (95\% confidence interval (CI) $90.5 \%$ to $98.3 \%$ ) and specificity of $88.1 \%$ (95\% CI $77.8 \%$ to $94.7 \%$ ). This was independent of thrombolytic treatment. ${ }^{5}$

However, despite the widespread use of troponins, since the consensus document redefinition of MI in $2000^{2}$ there has not been a direct comparison with the "old" MI definition to allow historical calibration against complication rates. This study confirms that there is a gradient of risk of short term cardiac events associated with increasing troponin concentrations; however, it is not until concentrations of $>1.1 \mu \mathrm{g} / \mathrm{l}$ are reached that the in-hospital prognosis equates to that of patients classified according to the "old" WHO definition. At low concentrations, although now diagnosed as having suffered an MI by ESC/ACC criteria, patients are not at such high risk.

This study only describes short term in-hospital end points. A modest rise in cTnT in the setting of an anatomically important unstable plaque may have a very different long term prognosis to a patient with an identical troponin concentration but small full transmural infarction. Secondly our cTnT sample was taken 12 hours after onset of chest pain, as recommended for diagnostic purposes, whereas the studies which have correlated with infarct size and left ventricular ejection fraction have tended to sample either a peak result or cTnT at the plateau phase, usually 12-48 hours after onset of chest pain. ${ }^{5}$ The two groups, $\mathrm{CK} \geqslant 400 \mathrm{IU} / \mathrm{l}$ and cTnT $>1.1 \mu \mathrm{g} / \mathrm{l}$, contained different individual patients and of the 250 patients with $\mathrm{CK} \geqslant 400 \mathrm{IU} / \mathrm{l}$, less than half $(\mathrm{n}=115)$ also had a troponin concentration $>1.1 \mu \mathrm{g} / \mathrm{l}$. Of the 135 patients with $\mathrm{CK} \geqslant 400 \mathrm{IU} / \mathrm{l}$ and troponin $\leqslant 1.1 \mu \mathrm{g} / \mathrm{l}$ the majority had raised troponins, mostly in the $0.27-1.1 \mu \mathrm{g} / \mathrm{l}$ range. This highlights the importance of using biochemical markers within the overall clinical context rather than in isolation. While the patient groups identified by CK $\geqslant 400 \mathrm{IU} / \mathrm{l}$ and $\mathrm{CTnT}>1.1 \mu \mathrm{g} / \mathrm{l}$ are not identical, the cohorts do have the same short term risk.
Lastly, the sample studied may not be representative of the totality of patients presenting, as the sample consisted of patients in whom both cTnT and CK were available, perhaps excluding some patients with larger ST elevation infarcts in whom only CK would have been measured.

This study suggests that in the setting of acute coronary syndrome, a 12 hour cTnT concentration $\leqslant 1.1 \mu \mathrm{g} / \mathrm{l}$ confers a better short term prognosis than that traditionally assigned to patients with MI. Only when cTnT exceeds this concentration do complication rates become comparable with the old CK based definition of MI.

\section{Authors' affiliations}

C J Knight, T R Keeble, A D Timmis, Department of Cardiology, London Chest Hospital, Barts \& London NHS Trust, London, UK

S Wilson, K Ranjadayalan, Department of Cardiology, Newham HealthCare NHS Trust, London, UK

J Cooper, The Rayne Institute, University College London, London, UK A Deaner, Department of Cardiology, Barking Havering and Redbridge NHS Trust, Barking, Essex, UK

Correspondence to: Dr Charles Knight, London Chest Hospital, Bonner Road, London E2 9JX, UK; knightlch@aol.com

Accepted 15 April 2004

\section{REFERENCES}

1 Joint International Society and Federation of Cardiology/World Health Organization. Nomenclature and criteria for diagnosis of ischaemic heart disease. Report on the joint International Society and Federation of Cardiology/World Health Organization task force on standardisation of clinical nomenclature. Circulation 1979;59:607-9.

2 The Joint European Society of Cardiology/American College of Cardiology Committee. Myocardial infarction re-defined-a consensus document of the Joint European Society of Cardiology/American College of Cardiology committee for the redefinition of myocardial infarction. Eur Heart $J$ 2000;21:1502-13.

3 Lindahl B, Venge P, Wallentin L, for the FRISC study group. Relation between troponin $T$ and the risk of subsequent cardiac events in unstable coronary artery disease. Circulation 1996;93:1651-7.

4 The multicenter postinfarction research group. Risk stratification and survival after myocardial infarction. N Engl J Med 1983;309:331-6.

5 Rao ACR, Collinson PO, Rose AJ, et al. Prospective evaluation of the role of routine cardiac troponin $T$ measurement to identify left ventricular fraction $<40 \%$ after first myocardial infarction. Heart 2003;89:559-60. 